\title{
Partner PhDs: dual careers in grad school and beyond
}

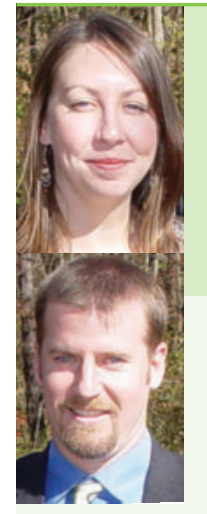

Jessica A Homyack* and Thomas A Gorman

Department of Fisheries and Wildlife Sciences, Virginia Polytechnic Institute and State University (Virginia Tech), Blacksburg, VA *(jhomyack@vt.edu)

Spousal hires are pertinent to professions in the natural sciences, where women and minorities remain underrepresented (NSF 2000). The proportion of women who choose careers in research is low, despite growing numbers of women earning $\mathrm{PhDs}$, a phenomenon referred to as the "leaky pipe" syndrome (Wickware 1997). Besides family responsibilities, nearly half of all women in science cite their spouse's employment as a limitation to their own career (NSF 2003). However, accommodating spouses during graduate school is equally important to encouraging and increasing diversity of women and minorities in academia and research. Potential future faculty develop perceptions about academia and further their career goals as graduate students. Currently, prospective graduate students must negotiate terms without the institutional infrastructure that may exist for faculty, and negative experiences are likely to discourage their continuation toward the tenure track.

Like many couples, we found the decision to return to graduate school difficult. The fact that we were seeking doctoral degrees in the same discipline added another layer of complexity. At the time, we were unaware of our options and were inexperienced negotiators but, luckily, after a short search we both received funded positions at the same institution. Throughout our tenure as doctoral students, we learned about strategic policies to accommodate dual-career faculty couples, yet saw limited infrastructures for recruiting partners into graduate programs. Most graduate student couples are unaware of their dual-career options as students or as future faculty, and will face professional, financial, and emotional barriers to success. Here, we provide advice - for graduate students navigating dual-career issues - from spouses who have worked toward $\mathrm{PhDs}$ together.

Flexibility emerged as an important attribute for dualcareer couples during a graduate search. Although a student may yearn to work with a specific person in a particular ecosystem, two funded positions are unlikely to be available at the same institution. So, broadening the scope of interests, widening the geographic search area, or accepting a more modest stipend or funding may be necessary (Benson 2006). Personal circumstances will increase the need to be flexible, and partners should decide jointly what they consider acceptable conditions before committing to a university. One couple that we spoke with, from a university in the Midwest, began with one spouse in a master's program and the other as a technician. Within 3 months, the technician received a funded assistantship, because he was willing to wait for a graduate position. Another couple made a list of universities with strong programs in their respective scientific fields, applied to several institutions, and attended the university that provided both with fully funded positions. Furthermore, they selected programs that allowed them to enter as doctoral students, to avoid having to search for both masters and subsequent $\mathrm{PhD}$ programs. These partners deviated from their ideal career plans, but were able to make choices that met the needs of both individuals.

Interviewed couples felt that it was also important for both partners to be highly competitive, and for those in similar fields to have expertise that complemented - not replicated - one another. In one interviewee's words, "you must be accepted as individuals". For partners in different disciplines, one spouse may be more in demand, simply because of the nature of the field. This can be used advantageously, where the more sought-after spouse may be able to negotiate strongly for a position for his or her partner. This strategy worked well for one couple, who secured PhD assistantships, post-docs, and, eventually, faculty positions at three different universities.

Identifying universities, departments, or specific faculty amenable to dual-career hiring will also increase the odds of success. Although we are unaware of any academic institution with related policies specific to graduate students, many universities have family-friendly policies for faculty that include accommodations for spousal hires. When gathering information about graduate programs, it may be useful to select universities where dual careers are common, and are considered an "opportunity" rather than a "two-body problem". An on-campus dual-career office, dual-career policies on the university webpage, or a National Science Foundation Advance grant are likely signs that the institution is supportive of spousal hires. A wealth of information regarding faculty spousal hires can be found in The Chronicle of Higher Education or discipline-specific publications (see WebTable 1 for a partial list); the advice may be useful for dual-career graduate students as well.

Finally, although the ability to negotiate is an essential skill for any would-be academic, few graduate students receive training in negotiating tactics and many 
are uncertain about the process (Bryant and Marks 2005). When possible, attending seminars or short courses on negotiation and encouraging universities to provide this training for graduate students will be useful. Many couples are unclear when to broach the topic of a spousal hire, but most people we interviewed recommended informing potential advisors during the on-campus interview. In our case, we informed our advisor early on in the interview process, which allowed us to attend on-campus interviews, meet with faculty, and experience the department together. Negotiations are far from an exact science, but being upfront about expectations and selling the dual career as an opportunity to have two excellent graduate students will be helpful.

In short, navigating graduate programs for dual-career couples can be a daunting task. However, adding flexibility, competence, negotiation skills, and patience will create a more productive search and, ultimately, two PhDs.

\section{Faculty response}

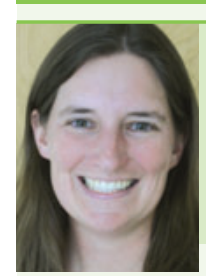

Kathryn (Kate) P Huyvaert

Assistant Professor, Department of Fish, Wildlife, and Conservation Biology, Colorado State University, Fort Collins, CO (huyvaert@warnercnr.colostate.edu)

Homyack and Gorman's piece offering advice for those dealing with the "leaky pipeline" and dual-hire issues early in their careers - as graduate students - is a timely one. Their experience is becoming increasingly common, as nearly one-third of women seeking, or about to seek, permanent positions in physics (and likely other STEM [science, technology, engineering, and math] disciplines) have spouses who are also scientists seeking employment (McNeil and Sher 2001). This is no surprise; we tend to be drawn to others with similar interests, goals, and values, and many people find strength and enjoyment in sharing the challenges and triumphs of their journey along their career path. Homyack and Gorman provide an excellent map for navigating a dual-career partnership from the earliest stages; to that I add some thoughts on making the most of it.

The authors advise dual-career couples to seek out universities or programs that see dual-hiring as an opportunity to mend the leaky pipeline rather than a two-body problem. Opportunity in this sense has an important flipside: prospective graduate students and job seekers should also be open to embracing opportunities as they arise. Opportunity is like serendipity waiting to be asked to dance: when a new situation comes up, don't hesitate to dance with the idea, to see if it is a chance worth taking. Imagine what our world would be like if Pasteur hadn't followed his own motto - "chance favors only the prepared mind" - in his work, which has led to today's germ theory and vaccinations. In addition to being prepared to grasp a good opportunity, partners that lag temporally - that is, your partner has secured a position or completed a degree before you have - can benefit by making opportunities to craft their own place as a professional. Homyack and Gorman counsel those partners in the same field "to have expertise that complements, not replicates each other". Seek or create opportunities to build a unique reputation. Offer to give a seminar in your spouse's or another department at the university (to show how your work is uniquely yours), take a class or two to broaden your options and strengthen your research profile, or try your hand at a research job that challenges you in a new way. Above all, be yourself as you progress together down your career paths.

\section{References}

Benson ES. 2006. Dual career couples. http://gradpsych.apags.org/ jan06/couples.html. Viewed 6 May 2008.

Bryant RA and Marks A. 2005. Go ahead, haggle. The Chronicle of Higher Education. Nov 8.

McNeil L and Sher M. 2001. Dual-science-career couples: survey results. http://physics.wm.edu/dualcareer.html. Viewed 8 Mar 2009.

NSF (National Science Foundation). 2000. Women, minorities and persons with disabilities in science and engineering: 2000. Arlington, VA: NSF.

NSF (National Science Foundation). 2003. Women, minorities, and persons with disabilities in science and engineering: 2002. Arlington, VA: NSF.

Wickware P. 1997. Along the leaky pipeline. Nature 390: 202-03. 